\title{
Very-long-term efficacy of bioresorbable vascular scaffolds
}

\author{
R. Shah ${ }^{1}$
}

To the Editor,

I read with great interest Elias and colleagues' recent metaanalysis in which 2-year follow-up data were used for all trials with the exception of ABSORB II [1]. However, sensitivity analysis using 2-year follow-up data from $\mathrm{AB}$ SORB II does not change their summary result for target lesion failure (TLF) (RR 1.31; 95\% CI 1.08-1.58; $p=$ 0.004). Thus, based on this meta-analysis, we can conclude that bioresorbable vascular scaffolds (BVSs) are associated with worse safety and efficacy outcomes up to 2 years after implantation; however, it is not clear if this is true beyond 2 years.

Since the publication of this work, two randomised controlled trials (RCTs) in addition to ABSORB II have reported 3-year results [2,3]. In ABSORB-Japan, only one scaffold thrombosis occurred $(0.4 \%)$ in the BVS group between years 2 and 3 [3]. The TLF rate was exactly the same (1.6\%) for both the BVS and metallic stent groups. In ABSORB-China, no stent thromboses occurred in either group between years 2 and 3 [2]. A landmark meta-analysis (using TLF between years 2 and 3 ) of these three trials suggests no statistically significant difference in TLF between the BVS and metallic stent groups (RR 1.78; 95\% CI 0.68-4.62; $p=$ 0.237).

These new findings suggest that efficacy problems with BVSs might recede 2 years post-implantation. While these findings are encouraging, they are not confirmatory; to be so, continued long-term follow-up of all relevant RCTs is needed.

Open Access This article is distributed under the terms of the Creative Commons Attribution 4.0 International License (http:// creativecommons.org/licenses/by/4.0/), which permits unrestricted use, distribution, and reproduction in any medium, provided you give appropriate credit to the original author(s) and the source, provide a link to the Creative Commons license, and indicate if changes were made.

\section{References}

1. Elias J, van Dongen IM, Kraak RP, et al. Mid-term and long-term safety and efficacy of bioresorbable vascular scaffolds versus metallic everolimus-eluting stents in coronary artery disease: A weighted meta-analysis of seven randomised controlled trials including 5577 patients. Neth Heart J. 2017;25:429-38.

2. Gao R. Randomized Comparison of Everolimus-eluting Bioresorbable Vascular Scaffolds vs. Everolimus-eluting Metallic Stents in Patients with Coronary Artery Disease: 3-year Clinical Outcomes from ABSORB China. Presented at: Annual EuroPCR Conference; May 17, 2017; Paris, France. Available at: https://www.tctmd.com/ slide/randomized-comparison-everolimus-eluting-bioresorbablevascular-scaffolds-vs-everolimus. Accessed 11 July 2017.

3. Kozuma K. ABSORB Japan: 3-year Clinical and Angiographic Results of a Randomized trial Evaluating the Absorb Bioresorbable Vascular Scaffoldvs. Metallic Drug eluting Stent in de novo Native Coronary Artery Lesions. Presented at: Annual EuroPCR Conference; May 17, 2017; Paris, France. Available at: https://www.tctmd. com/slide/absorb-japan-results-3-year-clinical-and-angiographicresults. Accessed 11 July 2017.
R. Shah

Shahcardiology@yahoo.com

1 Section of Cardiology, University of Tennessee, School of Medicine, Memphis, TN, USA 